\title{
Resgatando a paisagem tipográfica paulistana através de fotografias: um estudo piloto
}

\author{
Rescuing São Paulo city typographic landscape from photographs: a pilot study
}

Giovanna Lejanoski da Costa, Priscila Lena Farias

Letreiros, tipografia, história do design da comunicação

Este artigo apresenta alguns resultados de pesquisa que investiga letras presentes em mensagens comerciais inseridas na paisagem urbana paulistana nos primeiros anos do século XX. Através de levantamento, tratamento e análise de fotografias produzidas entre 1901 e 1930, e da comparação das letras encontradas nessas fotografias com aquelas encontradas em impressos do mesmo período, buscou-se identificar tendências e peculiaridades no uso de modelos de letras em diferentes suportes. Partindo de uma fotografia do início de 1910, letras grotescas, serifadas, escriturais, fantasias e toscanas, encontradas no espaço público, foram comparadas com famílias tipográficas utilizadas por impressores paulistanos nos cem primeiros anos de impressão.

Signs, typography, history of communication design

This article presents some results of a research that investigates letters present in commercial messages inserted in São Paulo city urban landscape in the first years of the $20^{\text {th }}$ century. Through the survey, treatment and analysis of photographs produce between 1901 and 1930, and by comparing the letters found in these photographs with those found in printed material from the same period, we sought to identify trends and peculiarities in the use of letter models in different media. Starting from a photograph from the early 1910s, grotesque, serif, scriptural, fantasy and tuscan letters found in public space were compared with typefaces used by São Paulo city printers in the first hundred years of printing.

\section{Introdução}

São Paulo tem notável importância histórica como polo industrial e comercial, devido a transformações decorrentes da Segunda Revolução Industrial no século XIX, e, no século seguinte, como polo gráfico. Neste período, a presença de mensagens comerciais fixadas nas fachadas das edificações (importante elemento arquitetônico da paisagem urbana) foi popularizada significativamente, configurando certo sentido de identidade, central para os estudos em memória gráfica. Midori (2002) detalha como a capital paulista se tornou um importante centro econômico durante a primeira república. Curitiba | Brazil | 2021 
Esta pesquisa investiga a presença de letras no espaço público nos primeiros anos do século XX no centro histórico de São Paulo, a partir da observação de fotografias que contenham exemplos de tipografia comercial ${ }^{1}$ em fachadas.

Pressupõe-se que a comparação entre letras fixadas na paisagem urbana e letras impressas do mesmo período possa contribuir significativamente para os estudos da memória gráfica. A partir do exame sistemático de fotografias, buscou-se identificar usos recorrentes de um mesmo estilo ou modelo de letra sobre diferentes suportes, e também de peculiaridades, como formas únicas ou pouco comum de letras na paisagem urbana.

No estudo piloto aqui apresentado, uma fotografia de autoria desconhecida foi examinada, chegando-se à identificação de letras grotescas, serifadas, de fantasia, escriturais e toscanas.

\section{Metodologia e desenvolvimento}

A estratégia utilizada baseou-se no "Protocolo de Pesquisa sobre Paisagens Tipográficas", criado pela equipe responsável pelo projeto Memória Gráfica Paulistana, desenvolvido na FAUUSP. Este protocolo busca definir um roteiro para estudos sobre paisagens tipográficas a partir de fotografias, detalhando como coletar e organizar essas imagens, como tratar os letreiros nelas presente, e, apresenta uma forma de analisar esses letreiros. Este material está em construção, portanto, as etapas aqui relatadas funcionam como testes para aprimorá-lo, sistematizando uma possibilidade de investigação sobre letras no ambiente urbano.

\section{Seleção e tratamento das fotografias}

A fotografia utilizada neste estudo piloto foi selecionada a partir do levantamento de um conjunto de imagens relevantes para o estudo da paisagem tipográfica comercial paulistana dos primeiros anos do século $X X^{2}$. Trata-se de 68 fotografias que contém fachadas de oficinas tipográficas, fotografadas entre 1901 e 1930 por Aurélio Becherini, Guilherme Gaensly e outros. Eles fazem parte do acervo do Museu da Cidade de São Paulo, do Museu Paulista ou foram encontradas em buscas na internet.

Foram selecionadas 22 fotografias do centro histórico de São Paulo e de seu entorno imediato, que apresentavam tipografia comercial nas fachadas das edificações, com resolução de $300 \mathrm{DPl}^{3}$. A fotografia apresentada na figura 1 foi escolhida para o estudo piloto pois continha maior diversidade de letras.

Para a obtenção de vistas frontais dos letreiros, uma vez que se apresentam em diferentes ângulos, foram realizados recortes e ajustes de perspectiva, utilizando o software Adobe

\footnotetext{
${ }^{1}$ Entende-se por tipografia comercial o conjunto de inscrições efêmeras, por exemplo aquelas presentes em pontos comerciais, incorporadas às edificações após sua construção e, na maioria das vezes, substituídas periodicamente (Farias, 2016, p. 147)

${ }^{2}$ A seleção de imagens partiu de um conjunto anteriormente identificado por Fábio Mariano Cruz Pereira, membro da equipe do Laboratório de Pesquisa em Design Visual (LabVisual) da FAUUSP.

${ }^{3}$ dots per inch, em português, pontos por polegada. Sigla da tecnologia utilizada para medir a resolução de imagens. Quanto maior o DPI, maior a resolução.
} 
Photoshop. Na fotografia selecionada (figura 1), 3 recortes foram identificados e manipulados. Recursos de 'distorção de perspectiva', 'transformação livre', com o auxílio de linhas-guias (figura 2), foram utilizados para se chegar às vistas. Em seguida, ajustando os níveis de luz, sombra, contraste e nitidez, obteve-se uma melhor visualização das letras presentes nos letreiros (figura 3).

Figura 1. Rua 15 de Novembro, 1910-1915, autoria desconhecida. Fonte: Museu da Cidade de São Paulo.

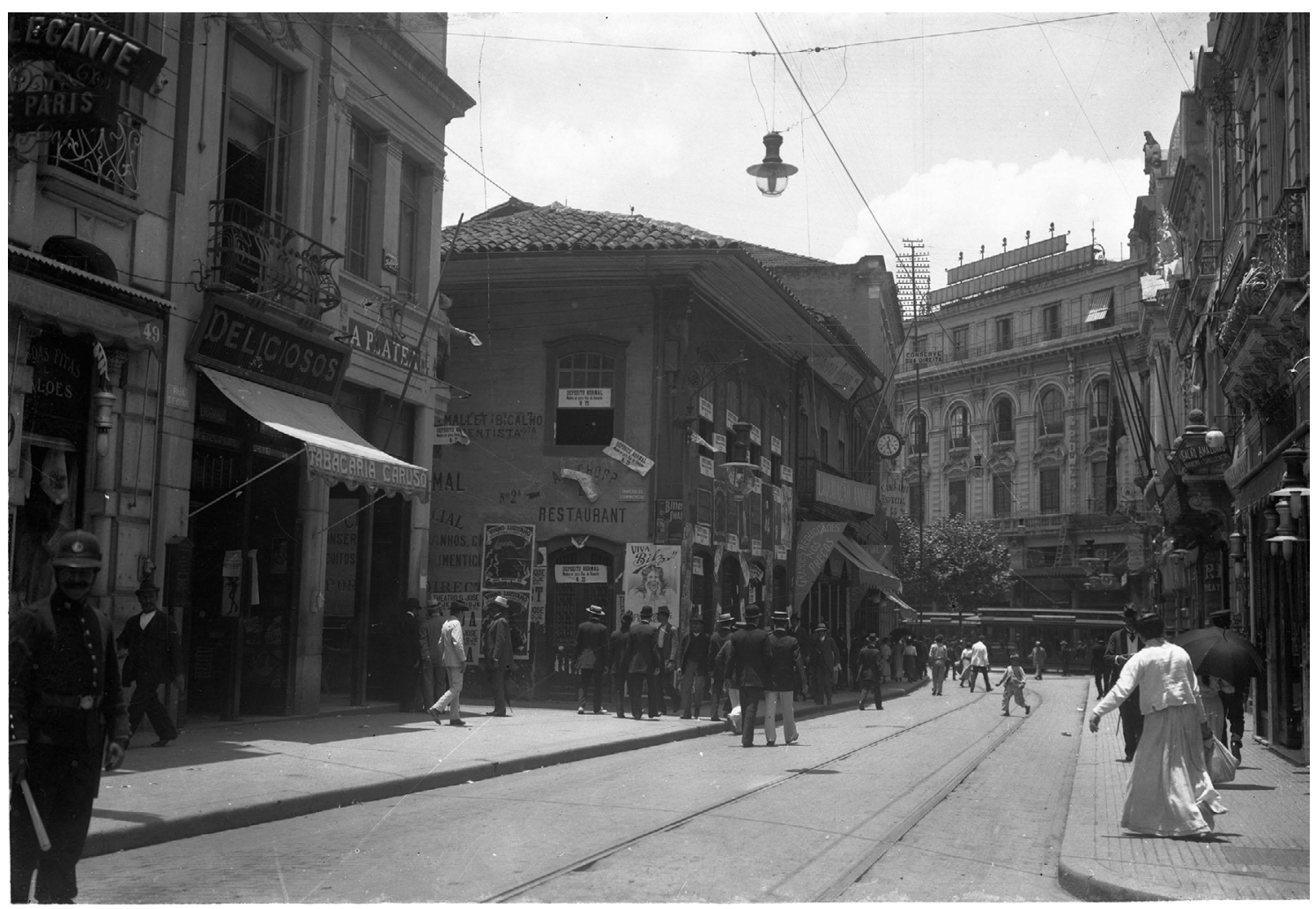

Figura 2. Detalhe da fotografia original comparado ao mesmo detalhe com perspectiva distorcida.

Presentes também as linhas-guias que auxiliaram na obtenção de visualização frontal.

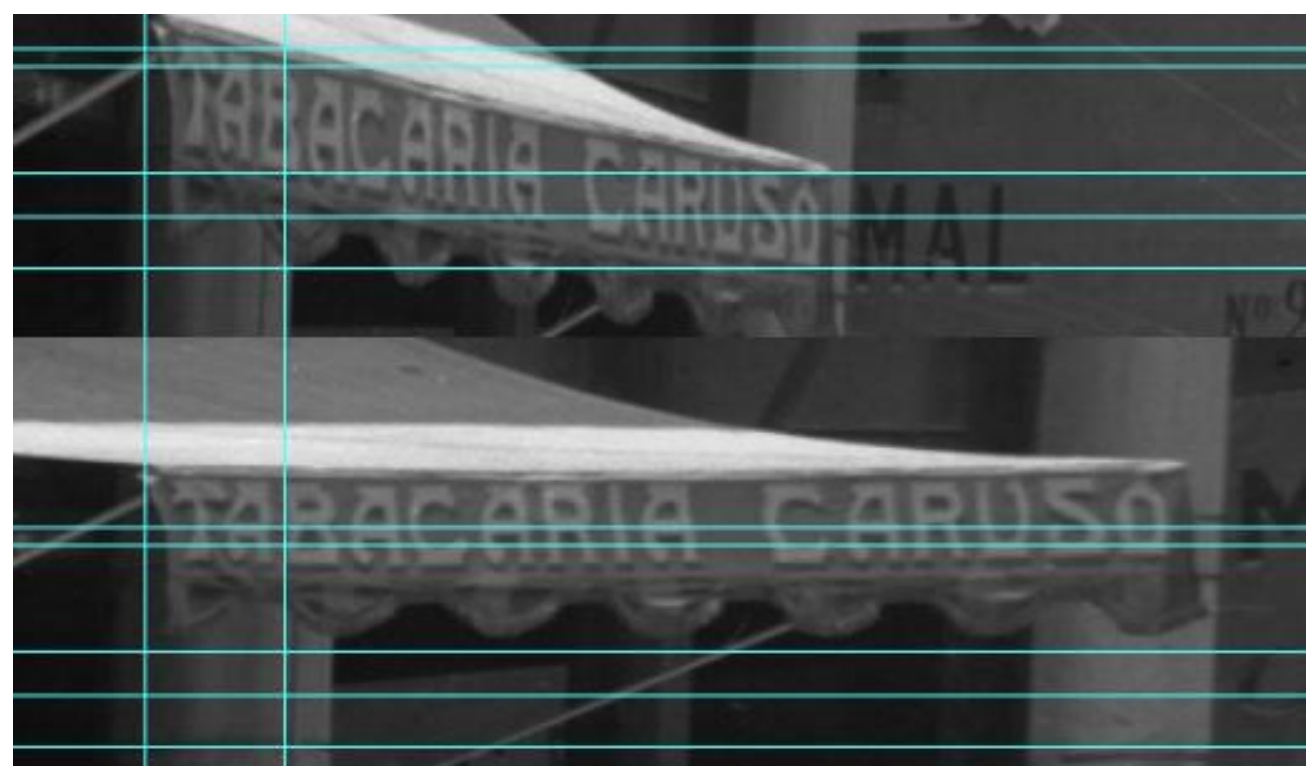


Figura 3. Vista frontal de letreiro ajustado em relação à luz, sombra contraste e nitidez.

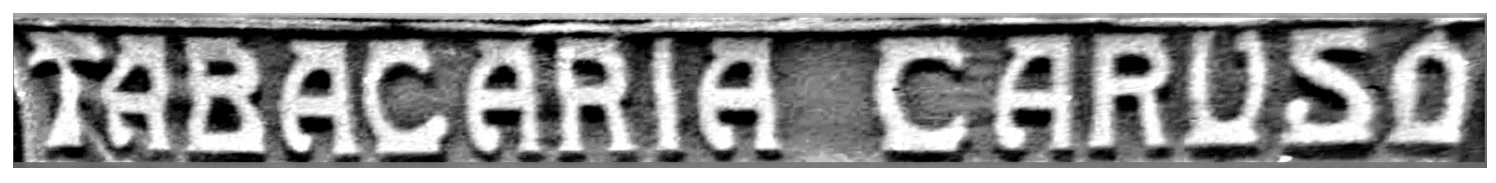

\section{Análise Comparativa}

Por meio de inspeção visual, foram feitas análises comparando os letreiros com thumbnails das famílias tipográficas disponíveis no site Tipografia Paulistana, na página Tipos ${ }^{4}$. Foram realizadas buscas filtradas e posterior navegação em páginas referentes a cada família.

Os caracteres das famílias tipográficas semelhantes aos letreiros foram usados para recompor as palavras dos mesmos letreiros. Espaços foram incluídos no lugar de caracteres ausentes.

\section{Resultados}

A fotografia analisada apresentou quatorze inscrições, incluindo três cartazes impressos colados nas fachadas (figura 4). As letras presentes nos onze letreiros restantes, todos aparentemente colados ou pintados sobre paredes ou toldo, foram comparadas com letras presentes na plataforma Tipografia Paulistana (tabela 1).

Figura 4. Cartazes impressos encontrados na fotografia apresentada na figura 1.

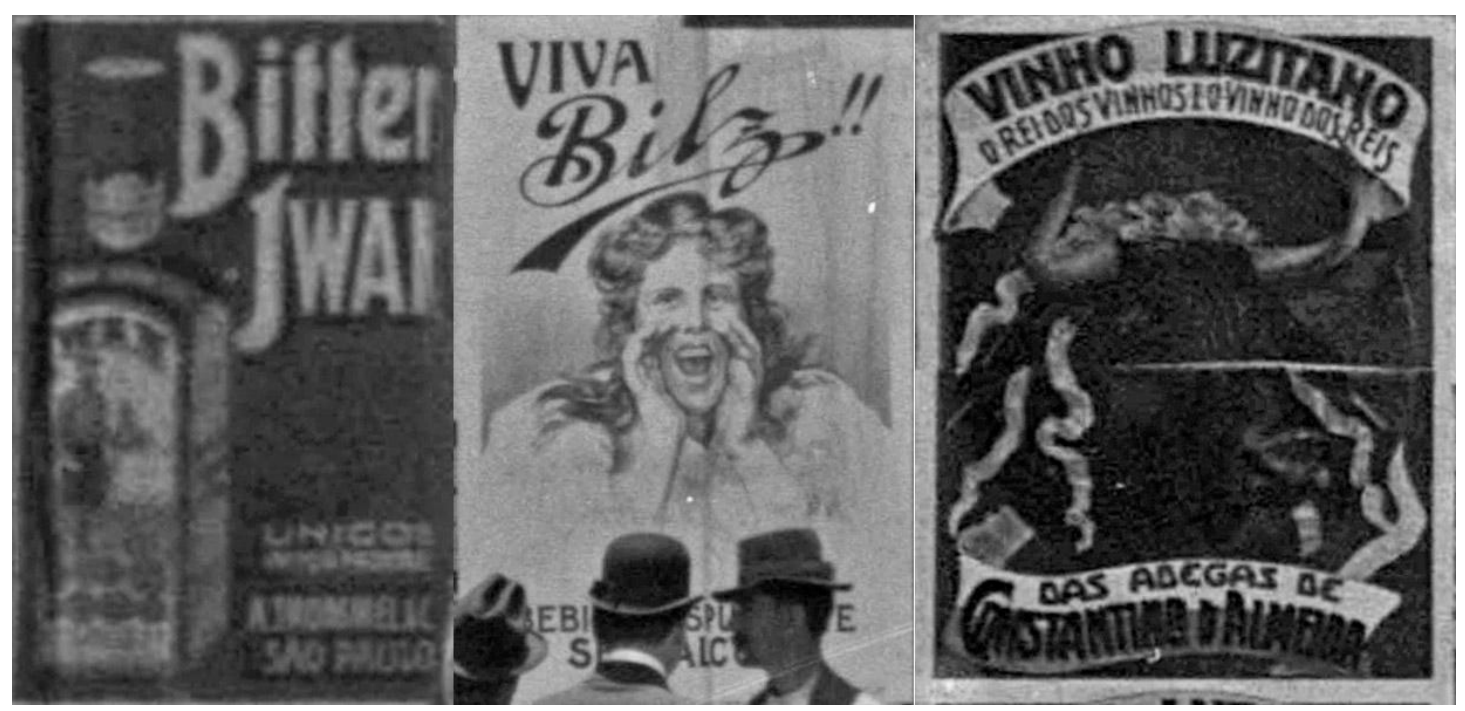

${ }^{4}<$ https://www.fau.usp.br/tipografiapaulistana/tipos/mosaico> 
Tabela 1. Comparações entre letreiros e letras presentes no site Tipografia Paulistana

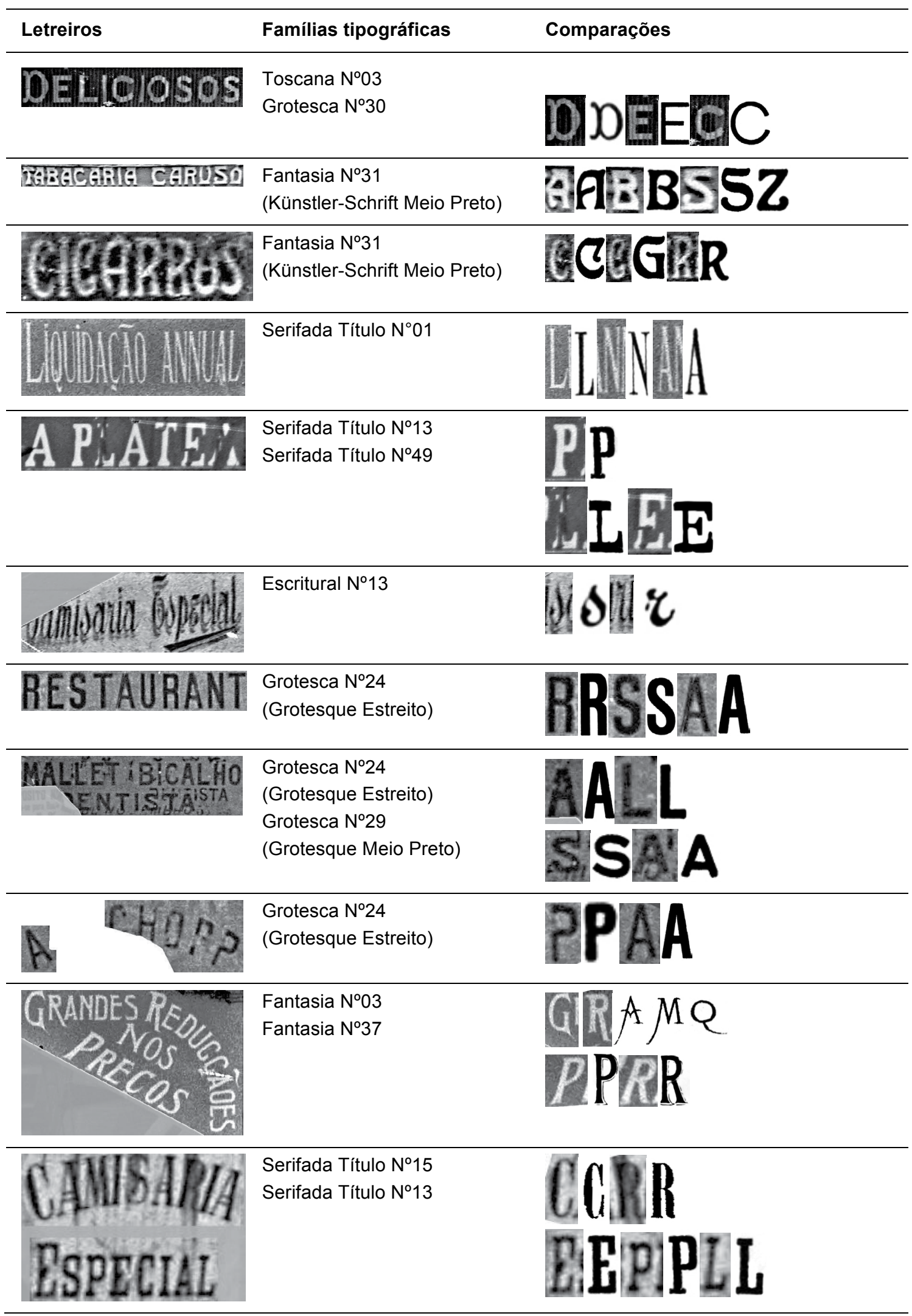




\section{Discussão}

Registrar letreiros comerciais não era, aparentemente, a intenção principal do autor da imagem analisada. Em todo caso, a fotografia é de um momento em que as fachadas e empenas cegas se apresentavam como suportes imponentes de comunicação. Assim, ao registrar um conjunto interessante de letreiros, torna-se um referencial para a pesquisa da paisagem tipográfica.

Uma breve análise dos dados apresentados na tabela 1 mostra que, em sua maioria, os letreiros presentes no centro histórico de São Paulo capturados pela fotografia apresentada na figura 1, eram formados por letras em caixa alta. Alguns deles apresentavam variações na altura do primeiro caractere em relação ao restante da palavra, configuração conhecida como 'versal/versalete' (ver figuras 5 e 6 ).

Percebe-se também que, apesar da diversidade dos letreiros, alguns formados por mais de um estilo tipográfico, a proporção entre letras de fantasia, grotescas e serifadas, é bastante equilibrada. Letras escriturais, por outro lado, aparece, apenas duas vezes, e as toscanas uma única vez (figura 5), como primeiro caractere (versal) de uma palavra na qual as letras restantes são menores (versaletes), e grotescas.

Figura 5. Letreiro, em versal/versalete, com letra inicial toscana e as restantes grotescas.

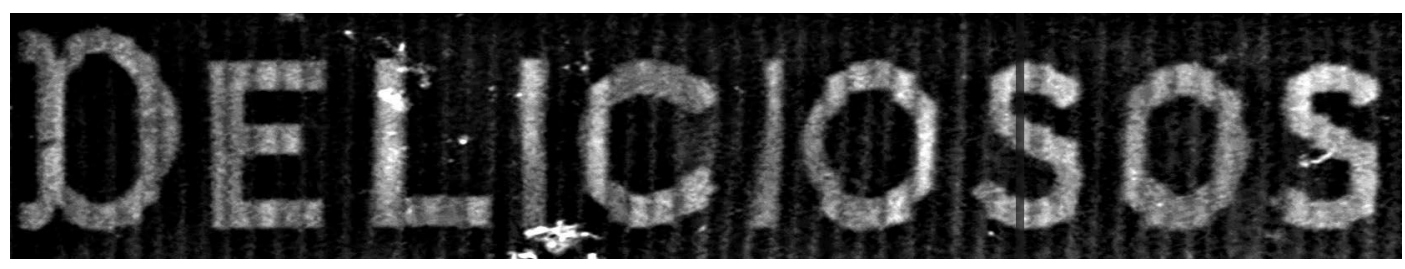

Os caracteres presentes em alguns letreiros se mostram ligeiramente condensados (tabela 1, figura 6). Entende-se aqui que alguma alteração pode ser resultado dos ajustes de perspectiva realizados, mas também que, por ser recorrente, esse tipo de distorção pode ser intencional.

Figura 6. Letreiro com letras condensadas.

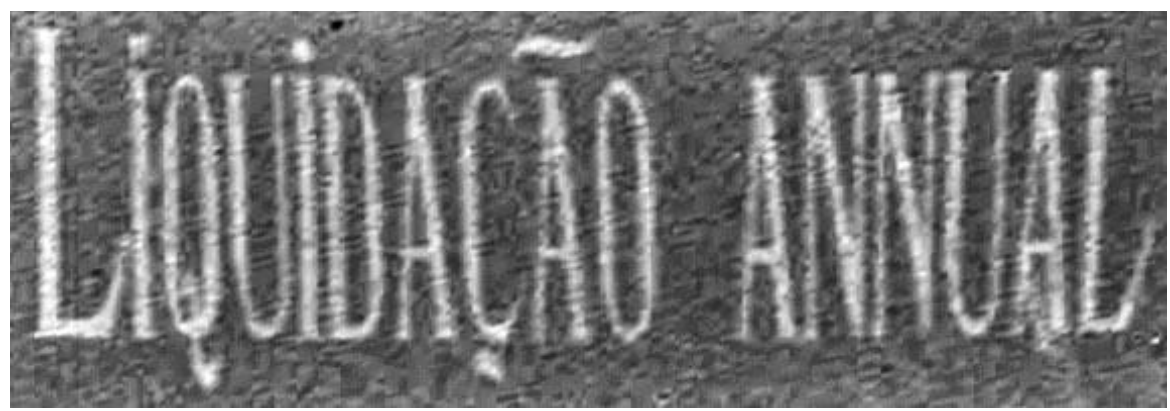

A análise comparativa entre as letras encontradas na fotografia e aquelas catalogadas na plataforma Tipografia Paulistana se deu mais facilmente em letras do estilo fantasia do que entre serifada e grotescas. A ornamentação presente no estilo facilitou essas comparações. Na análise do letreiro "GRANDES REDUCÇÃOES NOS PREÇOS" (tabela 1, linha 10), por 
exemplo, foi relativamente fácil identificar semelhanças com caracteres da família Fantasia $N^{\circ} 03$ - traços do $A$ e do $M$, cauda do $Q$, todos com terminações pontiagudas - que também foram encontrados no letreiro - perna do R, cauda do $G$.

Alguns casos de letreiros com letras semelhantes a mais de uma família tipográfica, e também, de uma família com letras semelhantes àquelas usadas em mais de um letreiro, foram observados. O tipo Fantasia №31 (Künstler-Schrift Meio Peto), apresenta letras semelhantes às do letreiro "TABACARIA CARUSO" (letras A e B), e um ornamento na letra $Z$ que se repete na letra S do letreiro (tabela 1, linha 2). Já na inscrição "CIGARROS" (tabela 1, linha 3), também são observadas semelhanças com letras da família Fantasia №31 (Künstler-Schrift Meio Preto), em versão condensada: a letra $A$ assimétrica, a forma do bojo do $R$ e sua relação com a haste, e o ornamento espiralado no terminal superior da letra $\mathrm{C}$, - este último presente também na letra $\mathrm{G}$ do letreiro, mas não na família tipográfica.

Em contrapartida, algumas comparações foram mais difíceis por não haver semelhanças claras entre as letras. Isso acontece, por exemplo, na inscrição "Camisaria Especial" em única linha, formada por letras escriturais (tabela 1, linha 6). As letras ' $r$ ' e 's' desta inscrição possuem semelhanças com aquelas da família tipográfica Escritural №13 encontrada na plataforma. Entretanto, a recomposição das palavras com letras da família tipográfica não se mostrou semelhante à inscrição fotografada.

Essa dificuldade pode ser reflexo de peculiaridades encontradas nos desenhos de letreiros. A plataforma Tipografia Paulistana é um site em construção, e letras novas são adicionadas constantemente. Apesar do número elevado de caracteres tipográficos já catalogados (304 famílias no momento da redação deste artigo), alguns dos letreiros observados pela cidade, realizados à mão, podem não ser cópia exatas de letras tipográficas pré-existentes, mas sim letras originais, pessoais, idiossincráticas. No entanto, mesmo as letras pintadas em letreiros que possivelmente se basearam em fontes tipográficas, por terem sido desenhadas à mão $\mathrm{e}$ em diferentes escalas, nunca serão idênticas às de uma fonte tipográfica.

\section{Conclusão}

Este artigo apresentou a análise de uma fotografia como forma de investigação da paisagem tipográfica paulistana nos primeiros anos do século XX. Através da comparação de letreiros encontrados nesta fotografia com letras de impressos do mesmo período, buscou-se a identificação de usos recorrentes de um mesmo estilo e desenho de letra, como também formas pouco comuns.

Capturando a rua 15 de Novembro em 1910, a fotografia de autoria desconhecida investigada apresenta um conjunto de onze letreiros e três anúncios nas fachadas comerciais do centro de São Paulo. Essa única foto mostra que no centro da capital paulista no início do século XX, letras escriturais, de fantasia, grotescas, serifadas e toscanas, em sua maioria em caixa alta, eram usadas em inscrições comerciais. Estas letras apresentam semelhanças com 
tipos presentes na plataforma Tipografia Paulistana. Ainda que não tenham sito encontradas letras idênticas, é possível inferir que letras impressas serviam como modelo para a criação de letras obtidas manualmente.

Neste estudo, a fotografia é colocada como importante fonte documental para investigação sobre letras na paisagem urbana. Análises realizadas a partir de um número maior de fotografias deve ajudar a entender melhor as escolhas tipográficas presentes em fachadas urbanas, contribuindo para o estudo da memória gráfica paulistana relacionada ao design da informação.

\section{Agradecimento}

Pesquisa realizada com apoio de bolsas PUB USP 2021 e PQ CNPq.

\section{Referência}

Farias, P. L. (2016). Estudos sobre tipografia: letras, memória gráfica e paisagens tipográficas. Tese de Livre-Docência, FAU-USP.

Farias, P. L. (2019). Visualizing data on graphic memory research. Selected Reading of the 8th Information Design International Conference: Memories. São Paulo: Blucher.

Farias, P. L.; Braga, M. C. (2018). Dez ensaios sobre memória gráfica. São Paulo: Blucher.

Midori, M. D. (2002). Comércio e vida urbana na cidade de São Paulo (1989-1930). São Paulo: Senac.

Tipografia Paulistana. (10 mai 2021). Tipografia Paulistana: Um acervo digital reunindo imagens dos tipos utilizados nas oficinas tipográficas instaladas na cidade de São Paulo entre 1827 e 1927. Disponível em https://www.fau.usp.br/tipografiapaulistana.

\section{Sobre o(a/s) autor(a/es)}

Giovanna Lejanoski da Costa, bolsista de Iniciação Científica, USP, Brasil <giovannalejanoski@usp.br>

Priscila Lena Farias, Professora Associada, USP, Brasil <prifarias@usp.br> 